\title{
Entre ruínas e viagens: memórias do deslocamento no documentário brasileiro, parte 2, Descaminhos
}

Gustavo Souza

Resumo: Este texto quer debater as configurações de uma memória do deslocamento no documentário brasileiro. Para isso, analisa o filme Descaminhos (Marília Rocha et al., 2007), cujo tema é a estrada férrea (ou o que dela sobrou) em quatro estados brasileiros. A intenção é verificar como a articulação entre depoimentos, imagens, sons e ruídos produz essa memória, em que se verifica uma recorrência ao trabalho e aos afetos relacionados ao trem. A hipótese adotada é que, em sua dimensão coletiva, a memória nesse documentário assume um aspecto de trajetória, cujas matérias-primas são a ruína e a viagem.

Palavras-chave: documentário; deslocamento; memória.

Abstract: Between ruins and travels: memories of dislocation in the Brazilian documentary, part 2, Descaminhos - This paper aims to discuss the configurations of a memory of dislocation in Brazilian documentary film. To that end, the documentary Descaminhos (Marilia Rocha et al., 2007) is analyzed focusing its theme, which is the railway - or what was left of it in four Brazilian states. The purpose is to verify how the connections of testimonials, images, sounds and noises produce that memory, in which there is a recurrence in the work and affections related to train. The hypothesis adopted here is that, in its collective dimension, memory takes the aspect of trajectory through the documentary, in which ruin and travel are basic components.

Keywords: documentary; dislocation; memory.

\section{Introdução}

Em trabalho anterior (SOUZA, 2015), debati as configurações de uma memória do deslocamento no documentário brasileiro por meio do filme Aboio 
(Marília Rocha, 2005), ao identificar a matéria-prima que compõe essa memória. Este texto dá continuidade a esse objetivo, seguindo o mesmo percurso ao privilegiar, agora, o documentário Descaminhos (Marília Rocha, Luiz Felipe Fernandes, Alexandre Baxter, João Flores, Maria de Fátima Augusto, Leandro HBL, Armando Mendz, Cristiano Abud, 2007) - reunião de seis curtas-metragens que apresentam em comum o mesmo tema: o trem. Os realizadores percorreram cidades do interior de Minas Gerais, Bahia e Rio de Janeiro que, no passado, se serviram da linha férrea hoje desativada, assim como fizeram as remanescentes viagens de trem comercial ainda realizadas no país. Nessa jornada, depararam-se com viagens que estão em vias de se extinguir ou com as ruínas de estações, trilhos e trens. É exatamente para esses dois aspectos - a ruína e a viagem - que este trabalho se volta.

Nos seis minidocumentários que compõem Descaminhos, há uma igual divisão na abordagem do deslocamento: em três deles seus personagens estão em movimento, em viagens atravessadas por relações afetivas, comércio, trabalho; nos outros três os personagens não se deslocam, eles geralmente aparecem em meio a ruínas e ao abandono gerados pela desativação da linha do trem em muitas cidades - principalmente, do interior de Minas Gerais. Num documentário que se autodenomina road movie, ${ }^{1}$ é válido perceber como está posta a questão do deslocamento, pois, para uma parte desses personagens, ele não é físico, uma vez que moram nas cidades por onde as equipes passaram, sugerindo um deslocamento metafórico que é, acima de tudo, da memória. Assim, pode-se adiantar que a relação entre fixidez e movimento está na gênese da memória do deslocamento fornecida pela obra.

A abrangência do conceito de memória, debatido por inúmeras áreas do saber, me faz adotar, de saída, a perspectiva sociológica de Maurice Halbwachs (2003), para quem a memória é sempre um acontecimento social. Se o indivíduo vive em sociedade, a formação de sua memória, embora individual e subjetiva, está sujeita às vivências experimentadas na coletividade. Desse argumento, surge o conceito de memória coletiva. Os depoimentos em Descaminhos corroboram esse ponto de vista, acionando para dois desdobramentos desta discussão: os embates entre a história oficial e a história vivida e a importância do testemunho dos mais velhos na construção desta memória. A perspectiva de Halbwachs é, como se vê, o alicerce deste trabalho, porém verificar que função assume essa memória coletiva no filme é também relevante. A hipótese adotada é que os elementos fílmicos deste documentário produzem uma memória como trajetória, cujas matérias-primas são a ruína e a viagem.

\section{Memórias das ruínas}

O segundo episódio de Descaminhos começa em Tocandira, no interior de Minas Gerais, uma cidade que já teve uma movimentada estação de trem e que hoje convive com

1 No DVD do documentário consta a seguinte sinopse: “Um road movie sobre trilhos através de quatro Estados, 55 cidades e $8.000 \mathrm{~km}$ de linhas férreas. Moradores às margens de ferrovias lembram o passado e comentam o presente a partir de um elemento comum: o trem". 
as ruínas desse tempo. Dois moradores relembram o período em que os trens passavam por ali e lamentam a desativação da linha férrea. Um senhor descreve a boa condição econômica dos moradores da região, devido à possibilidade de vender seus produtos, escoados pelo trem. "Eu lembro disso tudo! E vocês não lembram, né?", ele diz no término de sua fala ao revelar que tem 96 anos de idade. Num plano filmado em contra-plongée, uma senhora caminha pelos trilhos enferrujados enquanto ouvimos sua voz over relatar a variedade de produtos vendidos quando o trem parava na estação da cidade, gerando renda para os moradores, que, segundo ela, "choraram demais quando o trem acabou". E, num misto de curiosidade e desesperança, se pergunta: "Será que ele volta? Volta não". Em Barão do Guaicuí, também no interior de Minas Gerais, outra personagem se queixa que, depois que o trem parou de circular, acabou o movimento e muitas pessoas se mudaram, diminuindo também a oferta de trabalho.

Além da questão econômica, o que conecta os três depoentes deste segundo episódio é a evidência de uma memória em que se verifica uma dimensão pessoal, refletida, por exemplo, na fala do senhor que diz "lembrar de tudo isso", mas vivida com outras pessoas num determinado contexto social. Desse estratagema surge a memória coletiva (HALBWACHS, 2003), ou seja, lembranças comuns, umas apoiadas nas outras, mas que são tomadas de empréstimo do ambiente onde cada pessoa vive, podendo apresentar intensidades e materialidades diferentes. Essa perspectiva torna-se o alicerce do debate, que identificará o modo como essa memória opera, bem como aquilo que a compõe.

Enquanto as falas retomam a efervescência do passado, as imagens mostram vagões abandonados, trilhos enferrujados, estações deterioradas, as cidades-fantasma que se tornaram Tocandira e Barão do Guaicuí. São tomadas que se alternam entre planos muito próximos, como, por exemplo, os realizados dentro dos vagões, mas também planos gerais captam boa parte dessas cidades e as estações em ruínas. A alternância dessas imagens aciona a memória no plano imagético-narrativo num movimento entre aproximação e distanciamento que estabelece uma relação física com o passado em que se sobressai o signo da sobrevivência. Se a memória desse lugar está hoje materializada em ruínas, há, por outro lado, um esforço para localizar em meio às lembranças há tempos não ativadas os momentos mais significativos desse período. Esses personagens traçam um deslocamento que não é físico, mas cognitivo ou subjetivo, rumo a um passado repleto de experiências positivas em relação à ferrovia. Cria-se, portanto, um paradoxo entre as imagens e as falas, pois as primeiras revelam a decadência e o abandono, enquanto as segundas remetem ao movimento e à vivacidade antes da desativação de boa parte do sistema ferroviário. São personagens fixos de um road movie documental que traça, por meio da montagem, um percurso cujo término é a ruína. As falas estão no passado, as imagens as atualizam.

Porém, antes de testar a hipótese da memória como trajetória, é válido perceber como cada documentário articula, por meio dos principais temas que aborda, o material que a compõe. Em Descaminhos, há uma triangulação entre deslocamento, relações afetivas 
e de trabalho que perpassa, em diferentes níveis, os seis episódios do documentário. No primeiro deles, há uma narração em off de uma mulher que conta como conheceu um rapaz durante a viagem de trem com quem mais tarde viria a se relacionar. No entanto, para além dessa narrativa em que a questão do afeto é mais nítida, há também, de modo implícito, no quarto episódio, a exposição de um vínculo afetivo com o trem por parte dos moradores, assim como pelos ex-funcionários da ferrovia, presentes em seus depoimentos e que comentarei adiante. Em Descaminhos, apesar das inúmeras situações e experiências proporcionadas pelo trem, os vínculos afetivos figuram como importante material na formação dessa memória do deslocamento e que encontra nos depoimentos um lugar privilegiado. Ao debater a relação entre documentário e memória, Niney (2002) apresenta um argumento que se mostra útil:

A memória não é um problema de acumulação de informação, mas de assimilação e de esquecimento, de condensação e deslocamento: sem esse trabalho afetivo de integração, mas também coletivo de objetivação da história, com suas rejeições e achados, com seus pontos cegos e descobertas, não haveria atualização, um novo investir do sabido no vivido e do vivido no sabido, nenhuma história (NINEY, 2002, p. 248, grifo meu).

É possível identificar nesse argumento ecos das ideias de Halbwachs (a relação entre o vivido e o sabido) e Ricoeur (o esquecimento como parte formadora da memória) para uma melhor compreensão da relação entre a história e o "espírito do tempo" (NINEY, 2002, p. 248). É por meio dessas brechas (ou "pontos cegos") que a memória se molda ao imponderável da vida cotidiana, apresentando, consequentemente, uma dimensão que não se pretende fixa, mas adaptável às inúmeras vivências do dia a dia, como, por exemplo, a experiência do deslocamento. Por esse motivo as considerações de Niney, embora úteis, não serão tomadas literalmente, pois sua preocupação se volta para a relação entre história e memória, enquanto a minha, entre memória e deslocamento. É válido reter do seu argumento esse caráter maleável da memória em sua dimensão afetiva, uma vez que essa articulação que vai do pessoal ao coletivo não apenas constitui a memória, mas é também responsável por uma coesão social que favorece a adesão afetiva ao grupo, produzindo trajetórias, identificações e noções de pertencimento. A questão do trabalho é um desses componentes que aparece de modo significativo.

No quarto episódio de Descaminhos, esse tema surge nos depoimentos de ex-funcionários da linha férrea (agentes, maquinistas, construtores) que relatam como era o dia a dia do trabalho na ferrovia. Se, de um lado, moradores se perguntam sobre uma possível volta do trem, como no segundo episódio, alguns ex-funcionários também fazem essa pergunta - e, como os moradores, estão céticos sobre ela. Nesse caso, as dinâmicas do trabalho, como atividade extinta, só aparecem nos relatos (no máximo, vemos um dos depoentes vestido com o uniforme que usava no período em que estava em atividade). A entrevista funciona, portanto, como 
um espaço de memória ao resgatar, no vaivém da lembrança, as experiências relacionadas ao trabalho, deslocando da imagem para a fala o resultado das decisões político-econômicas adotadas há algumas décadas no país.

Soma-se a isso uma certa noção e aplicabilidade, bastante particular, é certo, de desenvolvimento e avanço tecnológico. Dito de outro modo: a partir do momento em que certas práticas profissionais deixam de existir em decorrência dos processos de globalização, o seu acesso ocorrerá por meio das falas dos entrevistados, uma vez que Descaminhos não recorre a encenações ou imagens de arquivo. Com essa opção, os realizadores tornam a palavra uma porta de aceso à memória, ainda que as imagens das ruínas, anteriormente comentadas, também figurem no plano imagético como um importante aspecto para sua a constituição. O equilíbrio entre o que se vê e o que se fala corrobora a importância do filme e do vídeo como veículos de transmissão de memórias, mas sem se ancorar apenas no depoimento (uma prática recorrente a muitos filmes de memória).

Na história do documentário, as imagens do trabalho se tornam mais recorrentes a partir dos anos 1930, especialmente a partir dos filmes realizados na Escola Inglesa liderada por John Grierson. O que mudou, dessa data até a atualidade, é o modo como essas imagens são incorporadas e seus possíveis desdobramentos analíticos. Para uma melhor compreensão das dinâmicas do trabalho no documentário contemporâneo, é preciso ponderar, seguindo as trilhas de Bondebjerg (2013), que os desígnios globais não se distanciam dos contextos nacionais. A maneira como o trabalho aparece em Descaminhos confirma essa perspectiva, mas, como especificidade brasileira, prevalece uma contradição porque, no contexto global, muitos países (europeus principalmente) ainda utilizam as ferrovias como meio de transporte, enquanto aqui se privilegiou o carro em detrimento do trem. Mais uma vez nos depoimentos é que se localiza essa dimensão. Nas falas de João, maquinista, ou de José, construtor, há tanto a descrição da rotina de trabalho como também o reconhecimento das "muitas amizades" e da "irmandade" no dia a dia da ferrovia. Saudosos dessa época, outros personagens se perguntam sobre uma possível volta do trem. Embora esta indagação já venha acompanhada de uma resposta negativa, dela se pode extrair a relação entre a memória e a projeção de um futuro desejado, ainda que improvável. Mais do que retórica, essa pergunta surge como sintoma de um desejo comum, de um passado ao qual se quer voltar ou do qual se quer o retorno sob a forma de um futuro idealizado. Prevalece nessas falas uma relação de afeto em relação à ferrovia, mas também um sentimento de abandono. Alguns personagens, como José, são enfáticos no seu diagnóstico: "Os políticos não olharam com amor para a linha férrea".

Essas falas ratificam mais uma vez a entrevista como um espaço de memória ao empreenderem uma revisão crítica do passado a fim de entendê-lo à luz das questões atuais. Em sua dimensão coletiva, a memória resulta da negociação entre o particular e o público, isto é, memórias só são possíveis quando compartilhadas entre quem conta e quem ouve. Ao articular o verbal (depoimentos) e o não-verbal (imagens das ruínas), 
mas sem privilegiar nenhum desses dois aspectos, o documentário remete a signos externos à lembrança e concebe à narrativa a possibilidade de apresentar uma memória que se projeta e se estende. Esse processo de transmissão, essencialmente seletivo, é que torna possível a memória como trajetória, afinal as ruínas que restam assim como as falas sobre a ferrovia não são a memória em si, mas são construídas como tal. Por isso, a sua dimensão de trajetória, uma vez que um determinado evento, contexto ou situação se torna o ponto de partida para perpetuar as trajetórias da memória para além dos períodos de vida dos indivíduos. Na noção de trajetória, o futuro é extremamente importante; afinal, é para as gerações futuras que uma possível "construção do mundo" se projeta.

Da admiração e dedicação de antes, o que resta hoje para ex-usuários e exfuncionários é a ruína. Não à toa o quarto episódio começa exatamente com dona Renata, seu Gaspar e dona Estela percorrendo o que, no passado, foi a estação das cidades de Alpercatas e Sacramento, ambas em Minas Gerais. Outros personagens também são levados às ruínas da ferrovia e lá tecem seus comentários. Prevalecem nessas sequências planos em contra-plongée (normalmente utilizados para dar a impressão de grandiosidade ao que se filma) que estabelecem uma espécie de "rima" com a fala dos personagens, uma vez que elas sempre ressaltam o aspecto positivo da ferrovia. Tais ruínas são "autênticas" (HUYSSEN, 2014, p. 113), pois não se enquadram no desejo de preservação cada vez mais comum em muitas sociedades - desejo esse que não surge somente em prol da memória, mas também do turismo, destituindo das ruínas a sua autenticidade. Longe de se tornarem atrativas para restauradores, museólogos ou turistas, as ruínas nesse documentário compõem uma memória cujo sentido se desloca da atração para o binômio atraso/progresso, sendo o trem e o carro seus respectivos representantes. Trata-se de uma instância que está na história do país, mas que, na memória de quem viveu esse período, ganha uma configuração carregada de nostalgia; o argumento de Huyssen é útil para entender o fenômeno: "temos saudade das ruínas da modernidade porque elas ainda parecem encerrar uma promessa que desapareceu de nossa era: a promessa de um futuro alternativo" (2014, p. 93). Essas imagens, associadas aos depoimentos já comentados, apontam para os atritos entre a história oficial e a história vivida - aspecto importante para a compressão da memória coletiva, desdobrando-se, aqui, como um ponto a ser considerado no debate sobre a memória do deslocamento.

As ruínas nesse filme estão envoltas em um sentimento de perda e abandono, mas também ganharam outro uso na medida em que se tornaram local de moradia. No sexto episódio, um dos personagens mora na antiga estação de trem do bairro de Alfredo Graça, em Araçuaí, Minas Gerais. Mesmo deteriorado, o espaço foi visto como uma possível moradia e adaptado a esse propósito. De fato, ruínas podem ajudar a compor uma memória, mas há uma larga diferença entre visitar e habitar uma ruína. Embora inusitada, essa última opção desdobra-se como um modo de preservar as ruínas das ferrovias, pois habitar é também conservar, já que é preciso condições mínimas que permitam a instalação. 
Visitar e morar solicitam tempos diferentes, assim como estabelecem diferenças em relação ao espaço, delegando à visitação uma dimensão pública e à moradia, privada, em que pesam os sentidos de contemplação provisória e de necessidade básica, respectivamente. Essa sequência aciona a hipótese de que habitar as ruínas é o atual modo de preservá-las, de fazê-las não desaparecer com o tempo, uma vez que muitas delas estão totalmente abandonadas. Ao fazer o registro dessa situação, Descaminhos produz imagens que podem, inicialmente, ser vistas como denúncia do descaso do poder público, mas que também compõem uma memória que é a mescla do oficial e do vivido. O modo como a montagem articula essas imagens tensiona a relação entre passado e presente, produzindo "imagens dialéticas" (BENJAMIN, 1994), pois essa relação, como esclarece Löwy, não é unilateral, mas marcada por uma dialética em que "o presente ilumina o passado, e o passado iluminado torna-se uma força do presente" (LÖWY, 2005, p. 161). Nesse jogo, a imagem opera "sobrevivências", como propõe Didi-Huberman (2011) em sua discussão sobre esse conceito benjaminiano, cuja potência política articula dialeticamente passado, presente e futuro. Assim, a memória evoca o material fornecido pela história e encontra no documentário uma poderosa ferramenta para os rearranjos da memória como trajetória.

\section{Memória da viagem}

Enquanto os episódios dois, quatro e seis dão acesso às ruínas das ferrovias e aos depoimentos que resgatam o dia a dia dos trens em que se notam afeto e trabalho, nos demais episódios, o filme passa da fixidez ao movimento de três modos diferentes: primeiro, por meio de um relato em voz off de uma viagem feita por uma senhora (episódio um); em seguida, os realizadores acompanham os passageiros do trem que faz o trecho Belo Horizonte - Vitória (episódio três); e, por fim, a equipe acompanha um trabalhador rural (seu nome não é informado) numa viagem de Magé, no interior do estado do Rio de Janeiro, à Central do Brasil, no centro da cidade do Rio (episódio cinco).

$\mathrm{Na}$ introdução deste texto, comentei que o próprio documentário se intitula um road movie. O debate em torno desse gênero cinematográfico postula que, para haver road movie, é necessário que seus personagens estejam em deslocamento - seja de carro, ônibus, caminhão, trem ou, numa proporção mais rara, a pé. ${ }^{2}$ Os três episódios resumidos acima corroboram essa perspectiva, pois os seus personagens estão, de fato, se deslocando. Porém, nos três outros episódios, eles estão fixos, são moradores das cidades por onde as equipes passaram. Nesse caso, instaura-se uma questão para o road movie na sua vertente documental: é possível que ele exista com personagens fixos?

Antes de responder a essa pergunta, é preciso considerar que é personagem no documentário quem expõe o seu ponto de vista sobre algum tema ou quem expõe sua intimidade para também integrar a narrativa. Quem corrobora essa perspectiva são

2 Para mais detalhes, ver Cohan e Hark (1997), Corrigan (1991), Laderman (2002). 
os moradores ou ex-funcionários, mas não os realizadores. Como parte dos personagens se posiciona, mas não se desloca, quem fará esse percurso é a narrativa. Assim, no documentário, pode-se pensar em road movies cujo deslocamento se transfere do personagem para o plano narrativo - algo impossível na ficção, pois, como ação centrada nos personagens do roteiro, se eles não se deslocam não há road movie, uma vez que revelar os bastidores ou os dispositivos de filmagem só é possível no documentário (ou nos making of, como é bastante comum no campo ficcional).

A discussão em torno do road movie, especialmente no contexto norte-americano, postula como forte tendência de seus personagens estarem na contramão de regras, leis ou normas de conduta. Esse diagnóstico, entretanto, não se aplica totalmente a road movies realizados em outros países. Sobre a produção brasileira, Samuel Paiva (2009) já identificou que o trabalho é um aspecto central de inúmeros road movies. Mais que personagens outsiders, em diversos desses filmes há trabalhadores que têm no deslocamento um componente chave de sua atividade profissional. Descaminhos confirma essa prerrogativa de modo ainda mais radical, pois os trabalhadores que o documentário procura ouvir estão fixos, enquanto quem se desloca são os passageiros. É para esses personagens que as atenções se voltam a partir de agora.

No terceiro episódio do documentário, como sinalizado anteriormente, a equipe faz a viagem que vai de Belo Horizonte a Vitória, um dos últimos trechos a operar com trem de passageiros. ${ }^{3}$ Se nos road movies norte-americanos, de modo geral, prevalece o personagem que tem a marginalidade como estilo de vida, aqui essa exclusão não é uma opção e sim uma condição. O diretor João Flores ouve vários passageiros que justificam o uso do trem basicamente pelo baixo custo e também por ser mais confortável em relação ao ônibus. São também, em sua maioria, idosos aposentados ou que não conseguem mais trabalho, como relata um senhor que se queixa do preço da marmita vendida no trem: "Estou com 71 anos, não consigo mais trabalho, como vou pagar R \$ 6,00 por uma marmitex?". Esses personagens, mais que pessoas a esmo vivendo uma experiência hedonista, são a materialidade de um processo histórico que não reservou um lugar para eles.

No episódio em que a equipe faz a viagem rumo a Vitória, são entrevistados ao todo 16 personagens; desses, nove são idosos. A presença de personagens idosos só não é significativa no quinto episódio, cujo personagem central aparenta ter 40 anos. ${ }^{4}$ Voltarei a ele adiante. Por ora, é preciso frisar que há uma considerável presença dos mais velhos em todo o documentário. Como testemunhas de uma experiência já extinta (no caso dos personagens que vivem em cidades onde a linha férrea está desativada) ou em vias de se extinguir (outros se queixam das condições precárias dos trens em circulação atualmente), quem viveu esse momento tem melhores condições de relatá-lo. Na fricção entre a história oficial e a história vivida, "a presença de um idoso", como identificou Halbwachs (2003, p. 85),

3 O outro trecho em operação no país vai de São Luiz (MA) a Carajás (PA).

4 No episódio um, a narração é de uma senhora sobre a sua juventude, mas o seu rosto não é mostrado. 
"está de alguma forma impressa em tudo o que este nos revelou sobre um período e uma sociedade antiga, que ela se destaca em nossa memória". Nessas falas, verifica-se também a memória como trajetória, ou seja, um repertório que transmite informações e opiniões que muitas vezes não encontram espaço nos registros oficiais e históricos, mas que se torna também um veículo para a continuidade de um determinado valor ao ativar emoções em relação a pessoas e a objetos.

Ainda que a discussão tenha privilegiado até aqui questões econômicas, políticas e tecnológicas para o melhor entendimento do tema central de Descaminhos, os depoimentos desses personagens também tocam em questões pessoais ou subjetivas vinculadas ou não à temática do trem. Rumo a Vitória, um passageiro vê pela janela a represa da barragem da Usina Hidrelétrica de Aimorés. O que, no primeiro momento, poderia ser visto como a paisagem que a viagem proporciona é, para ele, motivo de emoção. Ali foi a cidade onde nasceu e cresceu. Chorando, ele aponta para a câmera o lugar onde jogava bola e onde morava. Isso denota o fato de o deslocamento não apenas modificar quem viaja (CORRIGAN, 2015; IANNI, 2000; KAPLAN, 1996), mas também ativar um trabalho de memória que é, antes de tudo, pessoal e afetivo. Nesse caso, as emoções não se limitam ao que o viajante experimenta durante o percurso com outros passageiros (como no primeiro episódio, em que a personagem relata a descoberta de uma paixão), mas se estendem também aos locais por onde esse personagem passará de trem. A viagem desenha uma memória que comunga o deslocamento com o espaço à sua volta.

Enquanto esse personagem traça um percurso que o conduz a suas vivências passadas, outro, no mesmo episódio, reflete sobre possíveis significados do ato de viajar. Ele diz: "a viagem de trem tem a ver com o acaso. O acaso é isso, é você se entregar. É uma situação que você não programa. A vida não é certeza, é possibilidade. É um exercício de prazer, lúdico, de risco". Ponto de vista próximo é o de lanni: "a viagem pode alterar o significado do tempo e do espaço, da história e da memória, do ser e do devir. Leva consigo implicações inesperadas e surpreendentes" (2000, p. 30, grifo meu). Desse modo, o depoente e o intelectual ajudam a entender os personagens desse documentário como sujeitos que deixam de ser predeterminados (outsiders, marginais, delinquentes...) para se moldar às transformações do espaço. A incerteza se torna uma condição elementar desse processo, um canal para a expressão da subjetividade. O sentido do deslocamento aqui é pautado na dúvida sobre si e sobre o contexto com o qual se depara, num esforço para construir um olhar para o mundo que é subjetivo, mas inteiramente relacional. O caráter transitório do deslocamento facilita o surgimento de impasses e desventuras, permitindo que a experiência de se deslocar construa para esses personagens novas experiências, outras expectativas, cujo alicerce é a incerteza sobre o mundo que o cerca, mas também sobre si. Ainda que os personagens se mostrem céticos em relação à volta da ferrovia nas cidades onde hoje ela está desativada, paira uma dúvida, em alguns casos angustiante, sobre a possibilidade de extinção dos trechos que ainda operam comercialmente. 
Tal incerteza ronda muitos desses usuários, que aproveitam o ensejo para externá-la em seus depoimentos. Se a ruína é o que restou aos moradores e funcionários da linha férrea, aos passageiros que ainda fazem essas remanescentes viagens restou também, por aproximação metonímica, ruínas - trens malconservados e inseguros.

Dos seis episódios de Descaminhos, em cinco há depoimentos sobre a experiência de viajar de trem ou sobre a relação com a ferrovia (como usuário ou funcionário). O quinto episódio é o único que destoa dessa recorrência. Nele, um homem vai de Magé ao Rio de Janeiro, com uma sacola na mão e uma enxada na outra. Ele não fala para a câmera, temos acesso apenas à sua imagem em planos abertos que se alternam com closes no rosto. Apesar do silêncio desse personagem, há uma profusão de sons diegéticos e extradiegéticos que também merecem atenção na discussão sobre a memória do deslocamento fornecida por este documentário. Há sons da natureza (correnteza de um rio e pássaros); esse mesmo personagem amolando a enxada na pedra; pessoas conversando no trem; o barulho do trânsito no centro do Rio de Janeiro. Em off, há duas falas: uma sobre o descaso com que a ferrovia é tratada e outra que se repete ao longo dos 11 minutos desse episódio em tom de eco: "O dinheiro é a segurança do homem, é a saúde e o dinheiro", além de uma música instrumental de um violão que perpassa todo o episódio.

Não é minha intenção estabelecer uma análise do som nesse documentário, o que fugiria aos propósitos deste texto, mas ressaltar apenas a relação entre silêncio (por parte do personagem) e ruídos (ouvidos desde o momento em que deixa a zona rural do Rio de Janeiro rumo à capital). Como o personagem não fala, não sabemos o motivo de sua viagem, se é usuário (frequente ou não) e que relação estabelece com a ferrovia, como se vê nos depoimentos dos outros episódios. Com esse personagem "enigmático", o documentário aborda a dicotomia entre o velho e o novo e entre o moderno e o arcaico. Pode-se deduzir que ele seja um trabalhador rural. Ao chegar ao centro do Rio de Janeiro com uma enxada na mão, ele destoa do ambiente em meio ao trânsito próximo à Central do Brasil. Ele não se insere num projeto de modernidade que desativa paulatinamente a linha férrea e força o homem do campo a migrar para os centros urbanos. Neste caso, há uma coincidência entre homem e máquina - ambos estão na mesma condição de exclusão, vistos como uma estranheza, uma peça que não se encaixa na engrenagem econômica atual. Seria o seu silêncio o reflexo de uma condição periférico-subalterna que não the permite falar? Assim, o que se ouve são ruídos, uma música instrumental e os depoimentos em off anteriormente descritos. São outros sons e outras falas que passam a integrar a experiência de uma viagem marcada, dentre outros aspectos, pela má conservação dos trens - ao burburinho da conversa entre os passageiros soma-se a zoada do trem que "agoniza" em suas viagens diárias. Desse modo, o episódio convida o espectador a "escutar ruídos" (COSTA, 2012, p. 155) que integram uma memória que é por excelência sensorial: feita de imagens, falas e sonidos. Afinal, podese descrever o estrondo da maria-fumaça, como faz um personagem em outro episódio, 
mas o arquivamento desse som como memória torna-se mais facilmente possível para quem o presenciou. Aos demais, resta o poder da imaginação, estimulada pela narrativa que recupera um barulho, um ruído, um determinado som.

\section{Conclusão}

A investigação de uma memória do deslocamento na produção documental contemporânea tem como tarefa identificar os elementos que compõem tal memória no espaço fílmico. Tais elementos em Descaminhos apontam para uma relação entre fixidez e movimento, materializada nas ruínas e nas viagens, respectivamente. Numa discussão que se propõe a debater a relação entre deslocamento e viagem, pode soar estranho utilizar a fixidez como uma categoria que integra essa memória. Porém, a fixidez de alguns personagens (os dos episódios dois, quatro e seis), assim como as imagens das ruínas que escancaram o abandono em relação à linha férrea, convive em paralelo com a lembrança de experiências que têm o deslocamento como aspecto central. A entrevista como um espaço de memória serve, então, para que os depoentes tracem um movimento que vai de sua experiência particular para o compartilhamento com o público. Essa instância que vai do pessoal ao coletivo é o que empresta a essa memória coletiva o seu aspecto de trajetória e que se ancora também nos depoimentos dos mais velhos para a sua transmissão.

Nesse documentário, o movimento promovido pela viagem distancia-se da sensação de liberdade ou quebra dos códigos hegemônicos, recorrente nos road movies norte-americanos. Essas viagens de trem, como se vê nos episódios três e cinco, ratificam a condição de exclusão por que passa parte da população, que, com poucos recursos, opta pelo deslocamento mais barato ou, quando a questão não é necessariamente financeira, usa o trem como uma estratégia para mantê-lo em funcionamento. Estratégia que é afetiva e utópica, pois, como outros depoimentos mostraram, a desativação da linha férrea escapa às vontades dos usuários. Essas viagens desembocam também na ruína, pois são muitas as falas sobre a má conservação e a insegurança nos trens que ainda operam. Há, sim, movimento, mas ele é circular, pois termina, de algum modo, na própria ruína. No entanto, o que aproxima essas duas dimensões - a ruína e a viagem - é a relação que estabelecem, cada uma à sua maneira, com afeto e trabalho, que aqui funcionam como as matérias-primas que preenchem a memória do deslocamento fornecida por Descaminhos. 


\section{Referências}

BENJAMIN, W. Obras escolhidas: magia e técnica, arte e política, vol. 1. São Paulo: Brasiliense, 1994.

BONDEBJERG, Ib. "Documentaries, work, and global challenges". In: MAZIERSKA, E. (org.). Work in cinema. Labor and the human condition. Nova York: Palgrave Macmillan, 2013.

COHAN, S.; HARK, I. R. (orgs.) The road movie book. Londres: Routledge, 1997.

CORRIGAN, T. Cinema without walls: movies and culture after Vietnam. New Brunswick: Rutgers University Press, 1991.

. O filme-ensaio. Desde Montaigne e depois de Marker. Campinas: Papirus, 2015.

COSTA, F. M. Silêncios, os sons do rios, os sons da cidade: Los muertos e Liverpool. Contemporânea - Comunicação e Cultura. Salvador, vol. 10, n. 1, p. 147-157, 2012.

DIDI-HUBERMAN, G. Sobrevivência dos vaga-lumes. Belo Horizonte: Editora UFMG, 2011.

HALBWACHS, M. A memória coletiva. São Paulo: Centauro, 2003.

HUYSSEN, A. Culturas do passado-presente: modernismos, artes visuais, políticas da memória. Rio de Janeiro: Contraponto, 2014.

IANNI, Octavio. Enigmas da modernidade-mundo. Rio de Janeiro: Civilização Brasileira, 2000.

KAPLAN, Caren. Questions of travel. Postmodern discourse of displacement. Durham: Duke University Press, 1996.

LADERMAN, D. Driving visions: exploring road movie. Austin: University of Texas Press, 2002.

LÖWY, M. Walter Benjamin: aviso de incêndio. São Paulo: Boitempo, 2005.

NINEY, F. L'épreuve du réel à l'écran. Essai sur le principe de réalité documentaire. Paris, Bruxelas: De Boeck, 2000.

PAIVA, S. A propósito do gênero road movie no Brasil: um romance, uma série de TV e um filme de estrada. Rumores - Revista de Comunicação, Linguagem e Mídias. São Paulo, vol. 3, n. 6, 2009.

SOUZA, G. Entre o personagem e a paisagem: memórias do deslocamento no documentário brasileiro, parte 1, Aboio. Revista Famecos: mídia, cultura e tecnologia. Porto Alegre, vol. 22, n. 2, p. 66-81, 2015. 